\title{
Langmuir-Hinshelwood kinetic model to capture the cobalt nanoparticles-catalyzed hydrolysis of sodium borohydride over a wide temperature range
}

\author{
J. Andrieux ${ }^{a}$, U.B. Demirci ${ }^{a, *}$, P. Miele ${ }^{a, b}$
}

a Université Lyon 1, CNRS, UMR 5615, Laboratoire des Multimatériaux et Interfaces, 43 boulevard du 11 Novembre 1918, F-69622 Villeurbanne, France

b Institut Européen des Membranes de Montpellier, Université Montpellier 2, CNRS, ENSCM, Place Eugène Bataillon, 34000 Montpellier, France

[*] Corresponding author. Tel.: +33 04724484 03; fax: +33 04724406 18. E-mail address: Umit.Demirci@univ-Iyon1.fr (U.B.Demirci).

\begin{abstract}
The present study focused on kinetics of hydrogen release through hydrolysis of sodium borohydride $\mathrm{NaBH}_{4}$ in the presence of cobalt nanoparticles. Our experimental conditions were quite severe as we worked over the widest temperature range ever reported (i.e. $10-90{ }^{\circ} \mathrm{C}$ ) and at high content of hydride (mol ratio $\mathrm{NaBH} 4 /$ water of 9; i.e. 18.9 wt\% $\mathrm{NaBH} 4$ or $6.18 \mathrm{~mol} \mathrm{~L}-1$ ). From the hydrogen evolution curves, the reaction constant versus the $\mathrm{NaBH} 4$ concentration, apparent activation energy, rate constant, adsorption constant and adsorption enthalpy were determined. It was noticed that the hydrolysis kinetics depends on (i) temperature of reaction and (ii) $\mathrm{NaBH} 4$ concentration. Hence, the kinetic constants were analyzed using existing kinetic models. The bimolecular LangmuirHinshelwood model satisfactorily captured the behavior of our catalyst consisting of cobalt nanoparticles (in our experimental conditions). Herein, the kinetic data, the kinetic model, the hydrolysis mechanism and the issues still to be addressed are reported and discussed.
\end{abstract}

\section{Key words}

Cobalt; Hydrolysis; Kinetic study; Langmuir-Hinshelwood kinetic model; Sodium borohydride. 


\section{Introduction}

Sodium borohydride (sodium tetrahydroborate; $\mathrm{NaBH}_{4}$; denoted herein $\mathrm{SB}$ ) is a hydrogen-rich compound that is known since the 1950s, namely since the Schlesinger et al.'s pioneer work [1]. More recently, it has attracted a great attention owing to its potential as solid-state hydrogen storage material (gravimetric hydrogen density GHD of $10.8 \mathrm{wt} \%$ ) and its potential as fuel of direct liquid-fed fuel cell (8-electron oxidation) [2]. Many efforts have since then concentrated on the former potential, with one of the challenges being to efficiently release the stored hydrogen. Hydrolysis of SB generates molecular hydrogen; it is a spontaneous reaction $\left(\Delta_{r} \mathrm{H}=-212 \mathrm{~kJ} \mathrm{~mol}^{-1}[3]\right)$, which can be easily implemented:

$\mathrm{BH}_{4}{ }^{-}(\mathrm{aq})+4 \mathrm{H}_{2} \mathrm{O}(\mathrm{l}) \rightarrow \mathrm{B}(\mathrm{OH})_{4}{ }^{-}(\mathrm{aq})+4 \mathrm{H}_{2}(\mathrm{~g})(1)$

However, the reaction is $\mathrm{pH}$-dependent and suffers from very slow kinetics. In other words, this reaction as such cannot be envisaged for technological applications. Otherwise, the hydrolysis can be easily (acid- or metal-) catalyzed, which enables to greatly improve the $\mathrm{H}_{2}$ generation rate (denoted $\mathrm{HGR}$ ) to reach values up to around $1000 \mathrm{~L}\left(\mathrm{H}_{2}\right) \mathrm{min}^{-1} \mathrm{~g}^{-1}$ (catalyst) [4]. All the same, SB has no potential as hydrogen storage system for vehicular applications because of high costs, low storage capacities and inefficient recyclability [5]. For example, the GHD of the system $\mathrm{NaBH}_{4}-2 \mathrm{H}_{2} \mathrm{O}$ is $10.8 \mathrm{wt} \%$ whereas that of $\mathrm{NaBH}_{4}-4 \mathrm{H}_{2} \mathrm{O}$ is $7.8 \mathrm{wt} \%$. In both cases, the gravimetric storage capacities in real applications should be at best 5.4 and 3.9 wt\% (assuming that the weight of $\mathrm{NaBH}_{4}-\mathrm{xH}_{2} \mathrm{O}$ is $50 \%$ of that of the storage system taken as a whole). The value $3.9 \mathrm{wt} \%$ is in fact the highest capacity that can be achieved in ambient conditions because the reaction is controlled by thermodynamics [6]. Yet, SB is still a promising solid-state hydrogen storage material for mobile, portable applications and that is why the current ultimate objective is today to make SB effective and viable for these applications [7].

Metal catalysis is much investigated in the literature devoted to SB hydrolysis. Although noble metals like Pt or Ru are highly reactive $[8,9]$, Co is the most attractive, being much cheaper and as reactive (in specific, optimized experimental conditions). To date, Co has been envisaged in various states and forms: Co salt (e.g. $\mathrm{CoCl}_{2}$ ), nanoparticles, supported over powdery support (e.g. $\mathrm{Al}_{2} \mathrm{O}_{3}$ or C), supported over substrate (e.g. Ni foam), alloyed with a metal (e.g. Ni), and doped (e.g. P as dopant) $[4,10]$. From the point of view of catalytic performances, the Co-based catalysts are generally efficient but most are not durable because they suffer from reactivity loss. Making a performing Co catalyst is currently not an issue anymore and this is maybe the reason why more and more studies are focusing on the reaction fundamentals. On the one hand, the (changing) state of the Co catalysts is investigated [11] and on the other hand the reaction mechanisms are considered on the basis of kinetics studies [12]. Kinetic studies and models are helpful highlighting reaction mechanisms. They 
enable to determine a reaction order versus the (initial and time-dependent) $\mathrm{NaBH}_{4}$ concentration ( $C_{0}$ or $C_{t}$, respectively), an order versus the $\mathrm{H}_{2} \mathrm{O}$ concentration and an apparent activation energy (EA). The orders can be exploited with few kinetic models such as the nth-order [13], LangmuirHinshelwood [12] and Michaelis-Menden [14]. For example, Zhang et al. [12] compared the nthorder and the Langmuir-Hinshelwood models and found that only the latter capture the kinetics of the Ru-catalyzed hydrolysis. It is noteworthy that several articles timely reviewed most of the kinetic data stemming from studies published so far (see e.g. Ref. $[10,13,15,16])$. The present study reports the main results of our kinetic study performed to better understand the SB hydrolysis catalyzed by commercial Co nanoparticles. It may be seen as the follow-up study of our work in reference [16], which mainly focuses on thermodynamics, catalyst characterization and kinetics on the temperature range $40-80^{\circ} \mathrm{C}$. Herein, we report a much more complete, detailed kinetic study. We observed that the catalyst has a changing behavior while e.g. the temperature increases from 10 to $90^{\circ} \mathrm{C}$. The data were analyzed with existing kinetic models and the kinetic parameters (e.g. reaction constant and apparent activation energy) were calculated over a wide temperature range, namely $10-90{ }^{\circ} \mathrm{C}$. The adsorption constant and enthalpy were also determined. Thereby, the reaction mechanism has been highlighted.

\section{Experimental}

SB (Acros Organics), $\mathrm{NaOH}$ (Sigma-Aldrich), Co nanoparticles (Strem Chemicals; ref. 27-0020) were used as received, stored and handled in an argon-filled glove box. Prior to hydrolysis experiment, the catalyst (10 wt\%) was mixed mechanically with SB (90 wt\%) in a mortar and the mixture transferred into a tube $(20 \mathrm{~mL})$ closed by a silicon stopper. The reactor was placed in a thermostatic bath. In a typical experiment, pre-heated distilled water (purged with Ar to remove $\mathrm{O}_{2}$ ) was injected into the reactor with a needle placed directly inside the bed of the mixture Co-SB. Note that this injection needle was immediately removed upon the water injection. An automated burette was used to control the water amount. The $\mathrm{H}_{2} \mathrm{O} / \mathrm{SB}$ molar ratio was equal to 9 (18.9 wt\% of SB or $\mathrm{C}_{0}$ of 6.18 mol. $\left.\mathrm{L}^{-1}\right)$. A second needle, also inserted in the tube through the stopper, enabled to evacuate the released $\mathrm{H}_{2}$ that was collected in an inverted water-filled graduated cylinder. The $\mathrm{H}_{2}$ volume was measured by video monitoring the water that displaced as the reaction proceeded. A thermal probe placed inside the SB bed measured the temperature during the reaction. The SB conversion, $\varepsilon(\%)$, was calculated as being the ratio of the experimental volume of $\mathrm{H}_{2}$ released at a given time to the expected maximum volume $\left(\varepsilon_{\text {tot }}(\%)\right.$ for the total conversion). The HGR ( $r, \mathrm{~mL} . \mathrm{s}^{-1}$ or $\left.\mathrm{L} \mathrm{min}^{-1} \mathrm{~g}^{-1}(\mathrm{Co})\right)$ was obtained by regression of the hydrogen evolution curves. Typically, it was determined by taking the slope of the curve on a defined range of SB conversion; it is noteworthy that the range was 
selected when it gave a linear regression coefficient such as $R^{2} \geq 0.997$. For the determination of the kinetic parameters, the overall system could be considered as a non-steady state slurry batch reactor.

\section{Results and discussion}

\subsection{Preliminary tests}

In reference [16], it is showed that hydrolysis in the presence of Co nanoparticles is catalytic. Typically, the HGR increases with the increase of the Co content from 1 to $10 \mathrm{wt} \%$. The plot as a function of shows a linear dependence, with a slope being of $0.8 \pm 0.1\left(R^{2}=0.99\right)$. In the present study, a similar test was performed, with the Co content varying from 0 to 20 wt\%. HGRs of $0.5,1.8$, 4.3, 6.9 and $10.0 \mathrm{~mL} . \mathrm{s}^{-1}$ were found for $0,5,10,15$ and $20 \mathrm{wt} \%$ Co. In the presence of Co, the total conversions were of about $95 \%$. The plot as a function of shows a straight line and the slope is $1.1 \pm$ $0.1\left(R^{2}=0.99\right)$, which confirms the datum above and, which is in agreement with values reported so far for e.g. Co nanoclusters [17], Co-B-based catalysts [18] and supported Pd/C [19]. The SB hydrolysis is thus purely catalytic in our conditions. The SB hydrolysis was carried out at ten different temperatures, namely $10,20,30,40,45,50,60,70,80$ and $90{ }^{\circ} \mathrm{C}$ (Fig. 1a). As expected, we observed that the higher the temperature is, the faster the $\mathrm{H}_{2}$ release is. Fig. $1 \mathrm{~b}$ shows the temperature variation ( $T_{\text {mes, }}$ as measured temperature) in the reactor. The variation may be divided into four stages, namely:

- A decrease from the set temperature $T_{\text {set }}$ because of the injection of water at lower temperature,

- An increase towards values higher than $T_{\text {set }}$ owing to the exothermic dissolution of $S B\left(\Delta_{d} H=-3.2\right.$ kJ.mol-1 [20]),

- A stabilization during the proper hydrolysis such as $T_{\text {mes }}>T_{\text {set, }}$ and,

- A decrease towards $\mathrm{T}_{\text {set }}$ upon the hydrolysis completion.

During the third stage, $T_{\text {mes }}$ was generally found to be higher than $T_{\text {set }}$ due to the exothermicity of the hydrolysis. For example, in the case of the hydrolysis performed at $60^{\circ} \mathrm{C}, \mathrm{T}_{\text {mes }}$ was $67^{\circ} \mathrm{C}$ after $45 \mathrm{~s}$ of reaction (conversion of about $55 \%$ ). Hence, $T_{\text {mes }}$ of the third stage was averaged $\left(T_{\exp }\right)$ and $T_{\exp }$ was used for the calculation of $E_{A}$. It is noteworthy that the difference between $T_{\text {set }}$ and $T_{\exp }$ was not higher than $6{ }^{\circ} \mathrm{C}$. Table 1 shows $T_{\text {set }}$ and $T_{\exp }, r$, and $\varepsilon_{\text {tot. }}$. These data were exploited in the kinetic study reported hereafter. 
Table 1. Main data stemming from Fig. 1.

\begin{tabular}{|c|c|c|c|c|c|c|}
\hline $\begin{array}{l}T_{\text {set }} \\
\left({ }^{\circ} \mathrm{C}\right)\end{array}$ & $\begin{array}{l}T_{\exp } \\
\left({ }^{\circ} \mathrm{C}\right)\end{array}$ & $\begin{array}{l}r \\
\left(\mathrm{~mL} \mathrm{~s}^{-1}\right)\end{array}$ & $\begin{array}{l}\Delta r \\
\left(\mathrm{~mL} \mathrm{~s}^{-1}\right)\end{array}$ & $\begin{array}{l}r\left(\mathrm{~L} \mathrm{~min}^{-1}\right. \\
\left.\mathrm{g}^{-1}(\mathrm{Co})\right)\end{array}$ & $\begin{array}{l}\Delta r\left(\mathrm{Lmin}^{-1}\right. \\
\left.\mathrm{g}^{-1}(\mathrm{Co})\right)\end{array}$ & $\begin{array}{l}\varepsilon_{\text {tot }} \\
(\%)^{\mathrm{a}}\end{array}$ \\
\hline 10 & 10.7 & 0.030 & 0.001 & 0.15 & 0.02 & 91 \\
\hline 20 & 21.7 & 0.120 & 0.001 & 0.52 & 0.06 & 84 \\
\hline 30 & 32.0 & 0.284 & 0.001 & 1.4 & 0.2 & 91 \\
\hline 40 & 43.0 & 0.656 & 0.003 & 3.2 & 0.4 & 90 \\
\hline 45 & 48.1 & 1.422 & 0.006 & 6.6 & 0.8 & 92 \\
\hline 50 & 54.2 & 1.606 & 0.007 & 7.9 & 0.9 & 89 \\
\hline 60 & 64.9 & 3.13 & 0.02 & 16 & 2 & 89 \\
\hline 70 & 71.2 & 4.90 & 0.03 & 25 & 3 & 87 \\
\hline 80 & 85.7 & 8.52 & 0.05 & 42 & 5 & 85 \\
\hline 90 & 90.2 & 8.74 & 0.06 & 43 & 5 & 76 \\
\hline
\end{tabular}

a The error was maximized to $2 \%$.
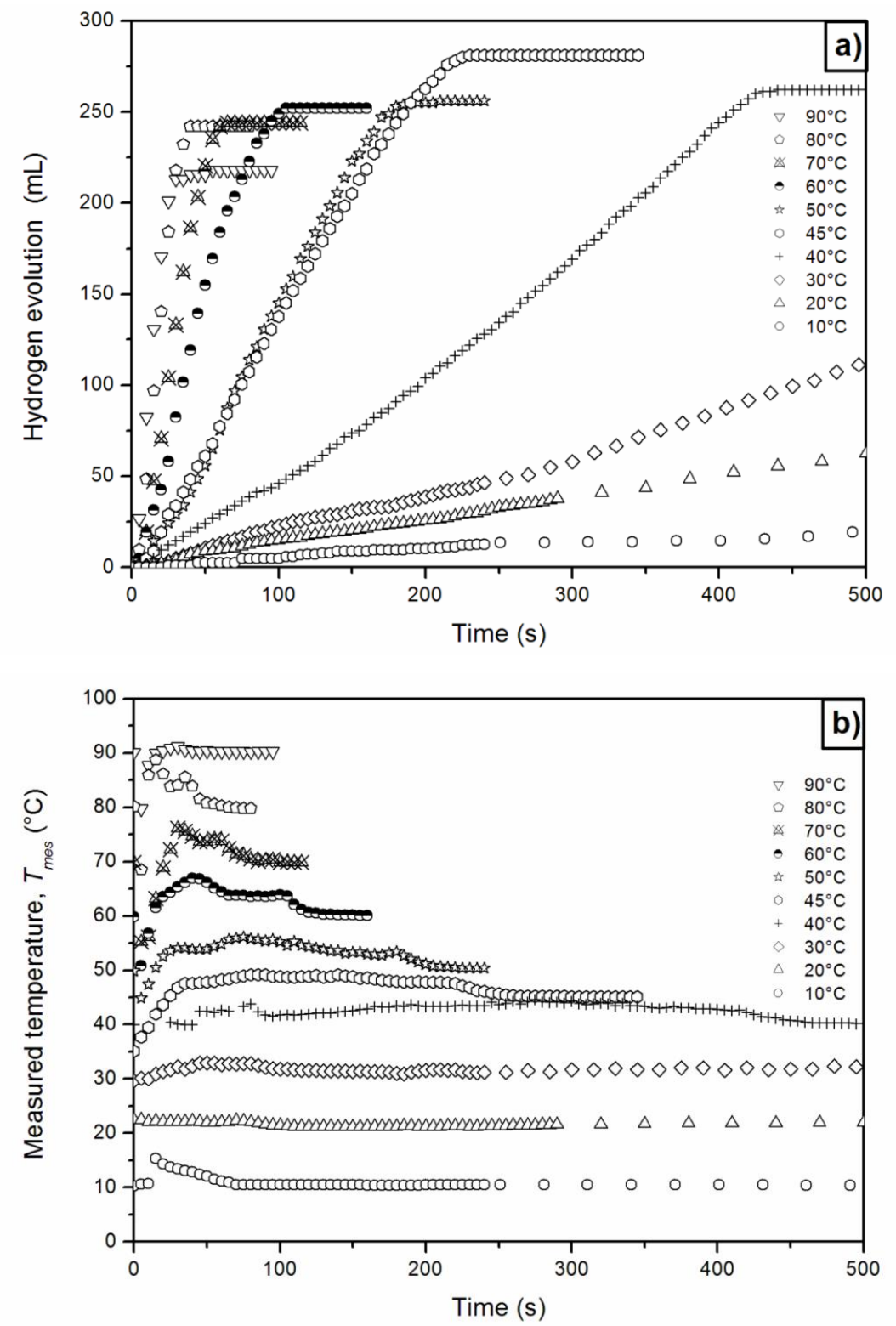

Fig. $1 . \mathrm{H}_{2}$ evolution at temperatures from 10 to $90{ }^{\circ} \mathrm{C}(\mathrm{a})$ and variation of $\mathrm{T}_{\text {mes }}(\mathrm{b})$. 


\subsection{Kinetic study}

The experimental data were used to graphically determine the reaction order $n$ versus $C_{t}$ and the energy $E_{A}$. Two kinetic models were considered: i.e. the $\mathrm{n}^{\text {th }}$-order and the Langmuir-Hinshelwood. It is noteworthy that the Michaelis-Menden and Eley-Rideal models were discarded; indeed, we have recently reported that both do not capture hydrolysis of SB in the presence of Co-based catalysts [21].

\subsection{1. nth-Order kinetic model}

Orders of 0,1 and 2 were considered; subsequently, the data in Fig. 1a were exploited in order to plot the variation of, and as a function of time. Fig. 2a depicts a typical example, namely the hydrolysis performed at $30{ }^{\circ} \mathrm{C}$.
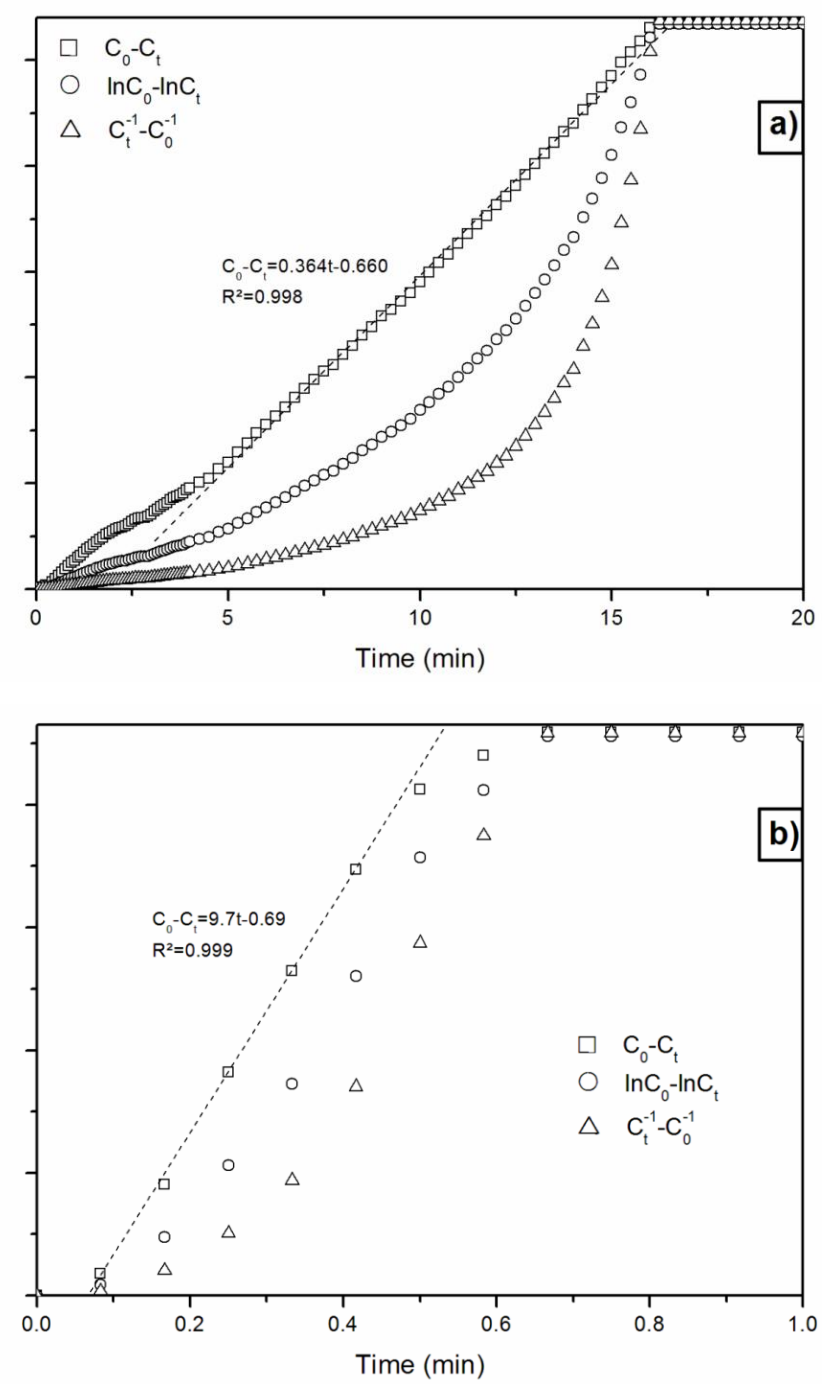

Fig. 2. Linear regression based on zero- (square), first- (circle) and second- (triangle) order for the hydrolyses performed at (a) $30^{\circ} \mathrm{C}$ and (b) $80^{\circ} \mathrm{C}$. 
First of all, it is important to note that we can distinguish two parts on the curves:

- The first part is quite irregular; it is ascribed to the T variations we discussed above. Therefore, this irregular part was not taken into account in the kinetic study.

- In the second part of the curves, $\mathrm{T}$ is stable; it was then taken into consideration this part of curves was analyzed.

Fig. 2a shows that the hydrolysis is zero-order at $30{ }^{\circ} \mathrm{C}$. An order of zero may be ascribed to dynamic saturation of the catalyst surface sites, with the saturation being induced by the $\mathrm{BH}_{4}{ }^{-}$ions. Further, it is generally observed at low $T[13]$ and high $C_{t}[15,22,23]$. And, in our conditions, $C_{0}$ was high, i.e. 6.18 mol. $L^{-1}$. The slope $\alpha$ obtained in the case of the zero-order linear regression (i.e. $0.364 \pm 0.002$ mol. $\mathrm{L}^{-1} \cdot \mathrm{min}^{-1}$ ) was then used to calculate the rate constant $\mathrm{k}_{0}$. It was found to be $0.014 \pm 0.003$ mol. $\min ^{-1} \cdot \mathrm{g}^{-1}(\mathrm{Co})$ at $30^{\circ} \mathrm{C}$.

The nth-order kinetic model (orders of 0, 1 and 2) was afterwards applied to each of the hydrolysis curves showed in Fig. 1a. Another example (hydrolysis at $80^{\circ} \mathrm{C}$ ) is depicted in Fig. $2 \mathrm{~b}$. The first- and second-order can be obviously discarded and the zero-order does not satisfactorily fit the data at the end of the hydrolysis. There is a noticeable bend at $t>0.41 \mathrm{~min}(\varepsilon>64 \%)$, which may be due to a change in the reaction order, such as $n>0$. Be that as it may, $k_{0}$ was calculated; it is of $0.41 \pm 0.09$ mol. $\mathrm{min}^{-1} \cdot \mathrm{g}^{-1}(\mathrm{Co})$ at $80^{\circ} \mathrm{C}$. Such a change was observed in each hydrolysis performed at $\mathrm{T}>45^{\circ} \mathrm{C}$. All of the $\mathrm{n}$ orders, $\alpha$ values and rate constants $\mathrm{k}_{0}$ are reported in Table 2 . Note that one can distinguish orders at high $C_{t}$ from orders at low $C_{t}$, with the former ones referring to the beginning of the hydrolysis and the latter ones to its end; the conversion $\varepsilon$ at which the change in $n$ occurred is also given. The order is zero at high $C_{t}$ over the range $10-90{ }^{\circ} \mathrm{C}$ whereas it is $>0$ at low $C_{t}$ (i.e. $\varepsilon>60 \%$ ) and $\mathrm{T}>45^{\circ} \mathrm{C}$. Our observations are consistent with Patel et al.'s [23] who observed that the reaction order versus $\mathrm{C}_{t}$ depends on the amount of $\mathrm{NaBH}_{4}$.

Table 2. Reaction orders $\mathrm{n}$ and rate constants $\mathrm{k}_{0}$ for the hydrolyses done at $10-90{ }^{\circ} \mathrm{C}$.

\begin{tabular}{|c|c|c|c|c|c|c|}
\hline $\begin{array}{l}T_{\text {set }} \\
\left({ }^{\circ} \mathrm{C}\right)\end{array}$ & $\begin{array}{l}n \text { high } \\
C_{t}\end{array}$ & $\begin{array}{l}n^{\mathrm{a}} \text { low } \\
C_{t}\end{array}$ & $\begin{array}{l}\alpha \\
\left(\mathrm{mol} \mathrm{L}^{-1}\right. \\
\left.\min ^{-1}\right)\end{array}$ & $\begin{array}{l}\Delta \alpha \\
\left(\mathrm{mol} \mathrm{L}^{-1}\right. \\
\left.\min ^{-1}\right)\end{array}$ & $\begin{array}{l}k_{0} \\
\left(\mathrm{~mol} \mathrm{~min}^{-1}\right. \\
\left.\mathrm{g}^{-1}(\mathrm{Co})\right)\end{array}$ & $\begin{array}{l}\Delta k_{0} \\
\left(\mathrm{~mol} \mathrm{~min}^{-1}\right. \\
\left.\mathrm{g}^{-1}(\mathrm{Co})\right)\end{array}$ \\
\hline 10 & 0 & 0 & 0.027 & 0.001 & 0.0014 & 0.0003 \\
\hline 20 & 0 & 0 & 0.127 & 0.001 & 0.005 & 0.001 \\
\hline 30 & 0 & 0 & 0.364 & 0.002 & 0.014 & 0.003 \\
\hline 40 & 0 & 0 & 0.748 & 0.007 & 0.029 & 0.005 \\
\hline 45 & 0 & $>080$ & 1.64 & 0.03 & 0.063 & 0.02 \\
\hline 50 & 0 & $>0^{71}$ & 1.96 & 0.03 & 0.08 & 0.02 \\
\hline 60 & 0 & $>065$ & 4.0 & 0.2 & 0.16 & 0.03 \\
\hline 70 & 0 & $>0^{67}$ & 6.3 & 0.6 & 0.28 & 0.07 \\
\hline 80 & 0 & $>064$ & 9.7 & 0.8 & 0.41 & 0.09 \\
\hline 90 & 0 & $>0^{60}$ & 10 & 2 & 0.5 & $0.2^{\mathrm{b}}$ \\
\hline
\end{tabular}

a In superscript is given $\varepsilon( \pm 2 \%)$ at which the reaction order $n$ changes.

b The error is high because the $\mathrm{H}_{2}$ evolution is very fast at $90^{\circ} \mathrm{C}$. 
In few of the kinetic studies reported up to now, it is showed that an order change can occur at high $\varepsilon$ (low $C_{t}$ ) [24,25]. Dai et al. [14] and Moon et al. [26] noticed that the kinetics of the SB hydrolysis cannot be captured only by an order of zero because $n$ depends on many experimental parameters such as the mol ratio catalyst/SB, the concentrations $C_{0}$ and $C_{t}$, and T. Zhang et al. [12] observed that the kinetics of the SB hydrolysis catalyzed by $\mathrm{Ru} / \mathrm{C}$ has a particular behavior; $\mathrm{n}$ increases with the increase of $\mathrm{T}$, being 0 at $25-55^{\circ} \mathrm{C}$ and 1 at $55-85^{\circ} \mathrm{C}$. This has been also reported elsewhere for $\mathrm{Ru} / \gamma \mathrm{Al}_{2} \mathrm{O}_{3}$ [13] and $\mathrm{CoCl}_{2} / \gamma \mathrm{Al}_{2} \mathrm{O}_{3}$ [27]. However, in both studies, the order is unaffected at constant temperature. As a result, we believe that, over the $\mathrm{T}$ range $45-90^{\circ} \mathrm{C}$, in our conditions, the change in $\mathrm{n}$ may be ascribed to the variations of $\mathrm{T}[12]$ and $C_{t}[23]$.

The logarithm of the $k_{0}$ values was plotted as a function of $T_{\exp }{ }^{-1}$ (Fig. 3a) in order to calculate $E_{A}$ over the range $10-90^{\circ} \mathrm{C}$. We had two approaches. The first approach was to fit all the data, which gave an of $63 \pm 3 \mathrm{~kJ} \cdot \mathrm{mol}^{-1}$. However, as one can see in Fig. $3 \mathrm{~b}$, there is a change in slope at around $45^{\circ} \mathrm{C}$. Hence, in a second approach, the logarithm of the $\mathrm{k}_{0}$ values at $\mathrm{T}<45{ }^{\circ} \mathrm{C}$ were plotted apart from the logarithm of $\mathrm{k}_{0}$ at $\mathrm{T}>45{ }^{\circ} \mathrm{C}$. In doing so, two $\mathrm{E}_{\mathrm{A}}$ values were obtained. At $\mathrm{T}<45{ }^{\circ} \mathrm{C}$, it was found to be $74 \pm 3 \mathrm{~kJ}$. mol ${ }^{-1}$. It compares favorably to energies of $70-75 \mathrm{~kJ} \mathrm{~mol}^{-1}$ found for $\mathrm{Ni}$ and Co catalysts [28] in experimental conditions similar to ours. At $\mathrm{T}>45^{\circ} \mathrm{C}, \mathrm{E}_{\mathrm{A}}$ was calculated as being $48 \pm 3 \mathrm{~kJ} \cdot \mathrm{mol}^{-1}$. It cannot be compared to values reported hitherto because, to our knowledge, $E_{A}$ has never been determined at $\mathrm{T}>40-50^{\circ} \mathrm{C}$. Further, a wider comparison to values available in the open literature seems irrelevant because of significant discrepancies in the experimental conditions. To summarize, there is thus a change in $E_{A}$ when $T$ increases. The decrease of $E_{A}$ may be ascribed to a change in reaction mechanism [29], specifically in rate determining step (RDS). This is discussed hereafter.

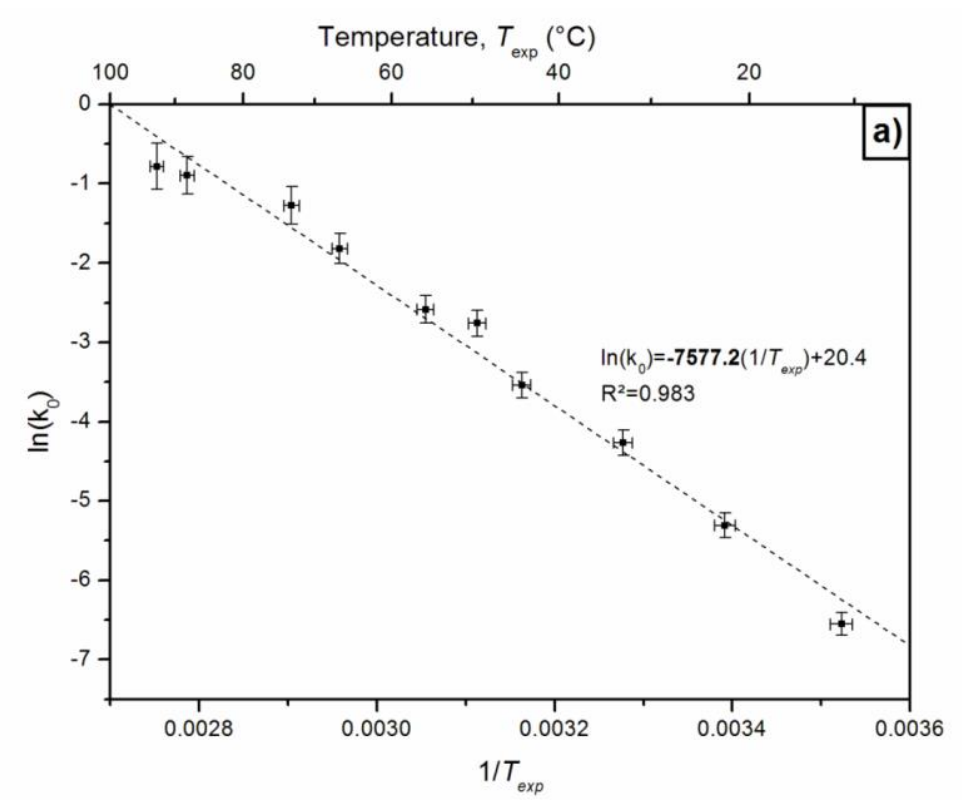




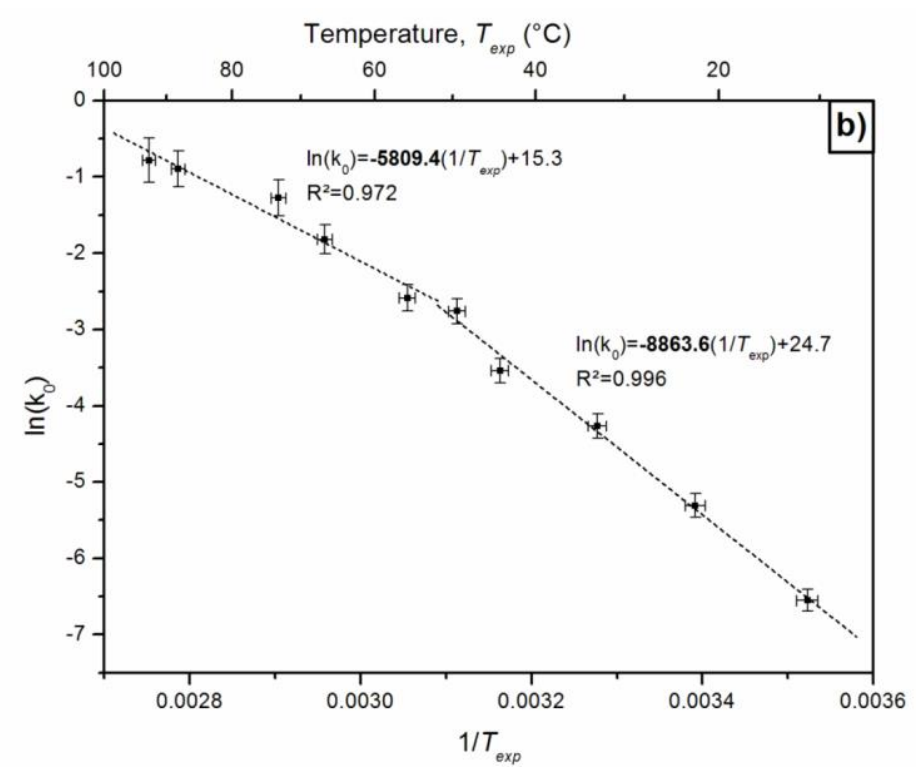

Fig. 3. Arrhenius plot for zero-order.

\subsubsection{Langmuir-Hinshelwood kinetic model}

To better understand the changes in $n$ and $E_{A}$, our results were analyzed on the basis of a more complex kinetic model, namely the Langmuir-Hinshelwood one, which captures the catalytic behavior of many metal catalysts $[12,13,21]$. This model, which mechanism is quite straightforward, is recommended for reactions occurring at high temperatures [13]. It takes into consideration the adsorption of both reactants, namely $\mathrm{SB}$ and $\mathrm{H}_{2} \mathrm{O}$, over the Co surface.

Similarly to Zhang et al. [12] (in their work, a change in $n$ was noticed when $C_{t}$ varied), we used the following equation (details of the model are available in Ref. $[12,13]$ ) in order to apply the LangmuirHinshelwood model:

$\left(C_{0}-C_{t}\right)+\frac{1}{K} \ln \left(\frac{C_{0}}{C_{t}}\right)=\left(\frac{m_{C o} k_{L}}{V}\right) t$

Though this equation has been reported in details elsewhere [12], it may be of interest to reader to briefly explain its origin and use. The reaction rate per unit of volume is described as:

$r=-\left(\frac{d C}{d T}\right)=\frac{m_{C o} k_{L} m \theta_{A}}{V}$

with $\mathrm{m}_{\mathrm{co}}$ the catalyst weight, the rate constant and, the surface coverage of $\mathrm{BH}_{4}{ }^{-}$that is given by the Langmuir adsorption isotherm:

$\theta_{A}=\frac{K C_{A}}{1+K C_{A}}$

with $\mathrm{K}$ the adsorption constant that is written:

$K=A \exp \left(-\frac{\Delta_{a d s} H}{R T}\right)=K_{0} \exp \left(\frac{\Delta_{a d s} H}{R T_{0}}-\frac{\Delta_{a d s} H}{R T_{\text {exp }}}\right)$

Combining Eqs. (3), (4) and (5), and then separating and integrating the as-obtained equation, Eq. (2) can be obtained. In this model, it is assumed that the reaction consists of two steps (equilibrated 
adsorption of $\mathrm{BH}_{4}{ }^{-}$on the Co catalyst surface and the reaction of adsorbed $\mathrm{BH}_{4}{ }^{-}$with $\mathrm{H}_{2} \mathrm{O}$ ). As water is in excess, its concentration is assumed to be constant. The Langmuir-Hinshelwood model and thus Eq. (2) are useful as they take into consideration the zero-order reaction at high (i.e.) and the firstorder one at low (i.e.) through K. To use Eq. (2), one has to plot as a function of According to the value of $\mathrm{K}$, there can be three situations: (i) the predominance of the zero-order kinetics at high $\mathrm{K}$; (ii) the predominance of the first-order kinetics at low $\mathrm{K}$; and, (iii) the combination of both orders (apparent order $n>0$ ). The value $K$ (Eq. (5)) depends on the equilibrium constant $K_{0}$ that is defined for a reference state, at $\mathrm{T}_{0}$ the temperature of the reference state ( $45{ }^{\circ} \mathrm{C}$ in our conditions), for $\Delta_{\text {ads }} \mathrm{H}$ the adsorption enthalpy of $\mathrm{SB}$ and $\mathrm{H}_{2} \mathrm{O}$, and at $\mathrm{T}_{\text {exp. }} \mathrm{K}_{0}$ and $\Delta_{\text {ads }} \mathrm{H}$ are characteristic of the Co catalyst.

From Eq. (2), $\mathrm{K}_{0}$ was determined and optimized as showed in Fig. 4. It was found to be $1.2 \pm 0.1$ L.mol ${ }^{-1}\left(R^{2}=0.99905\right)$. $K_{0}$ depends on both the catalyst nature and $T_{0}$. Zhang et al. [12] found a constant $\mathrm{K}_{0}$ of $220 \mathrm{~L}^{\mathrm{mol}}{ }^{-1}$ for $\mathrm{Ru} / \mathrm{C}$ at $25^{\circ} \mathrm{C}$. Hung et al. [13] calculated a $\mathrm{K}_{0}$ value of $1.96 \mathrm{~L}^{\mathrm{mol}}{ }^{-1}$ for $\mathrm{Ru} / \gamma \mathrm{Al}_{2} \mathrm{O}_{3}$ at $40{ }^{\circ} \mathrm{C}$.
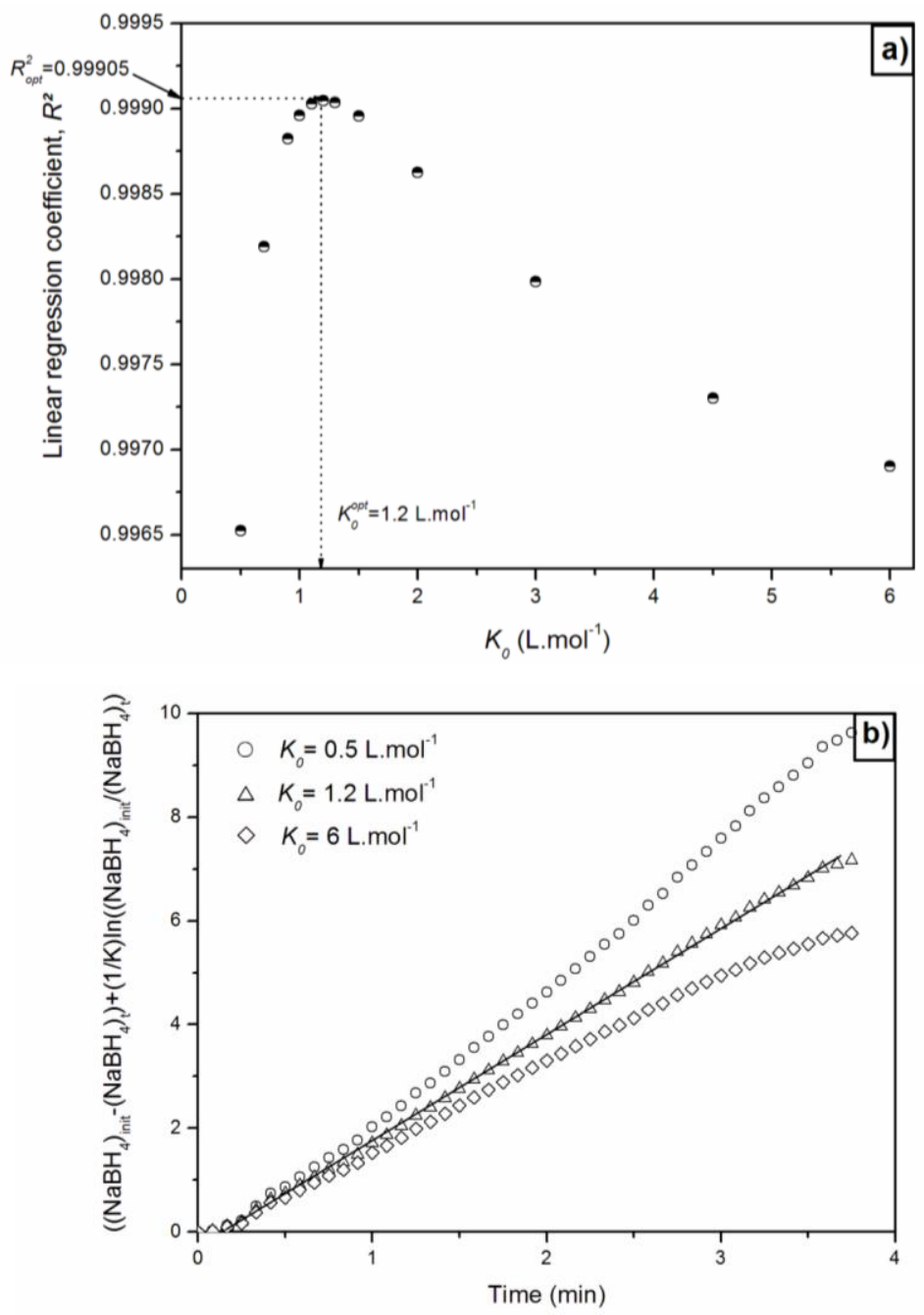

Fig. 4. Optimization of the adsorption constant $K_{0}$ for the Langmuir-Hinshelwood model in the case the hydrolysis at $45^{\circ} \mathrm{C}(\mathrm{a})$; the model diverges for $\mathrm{K}_{0}$ values different from $1.2{\mathrm{~L} . \mathrm{mol}^{-1}}^{(b)}$. 
From our $\mathrm{K}_{0}, \Delta_{\text {ads }} \mathrm{H}$ at $80{ }^{\circ} \mathrm{C}$ was then obtained (Fig. 5) and it is of $-33.0 \pm 0.5 \mathrm{~kJ} \mathrm{~mol}^{-1}\left(\mathrm{R}^{2}=0.994843\right)$. It is close to that found by Zhang et al. [12], that is, $-35 \pm 5 \mathrm{~kJ}^{\mathrm{mol}}{ }^{-1}$. From $\mathrm{K}_{0}$ and $\Delta_{\mathrm{ads}} \mathrm{H}, \mathrm{K}$ was found to be $0.33 \pm 0.04{\mathrm{~L} . \mathrm{mol}^{-1}}^{-1}$.
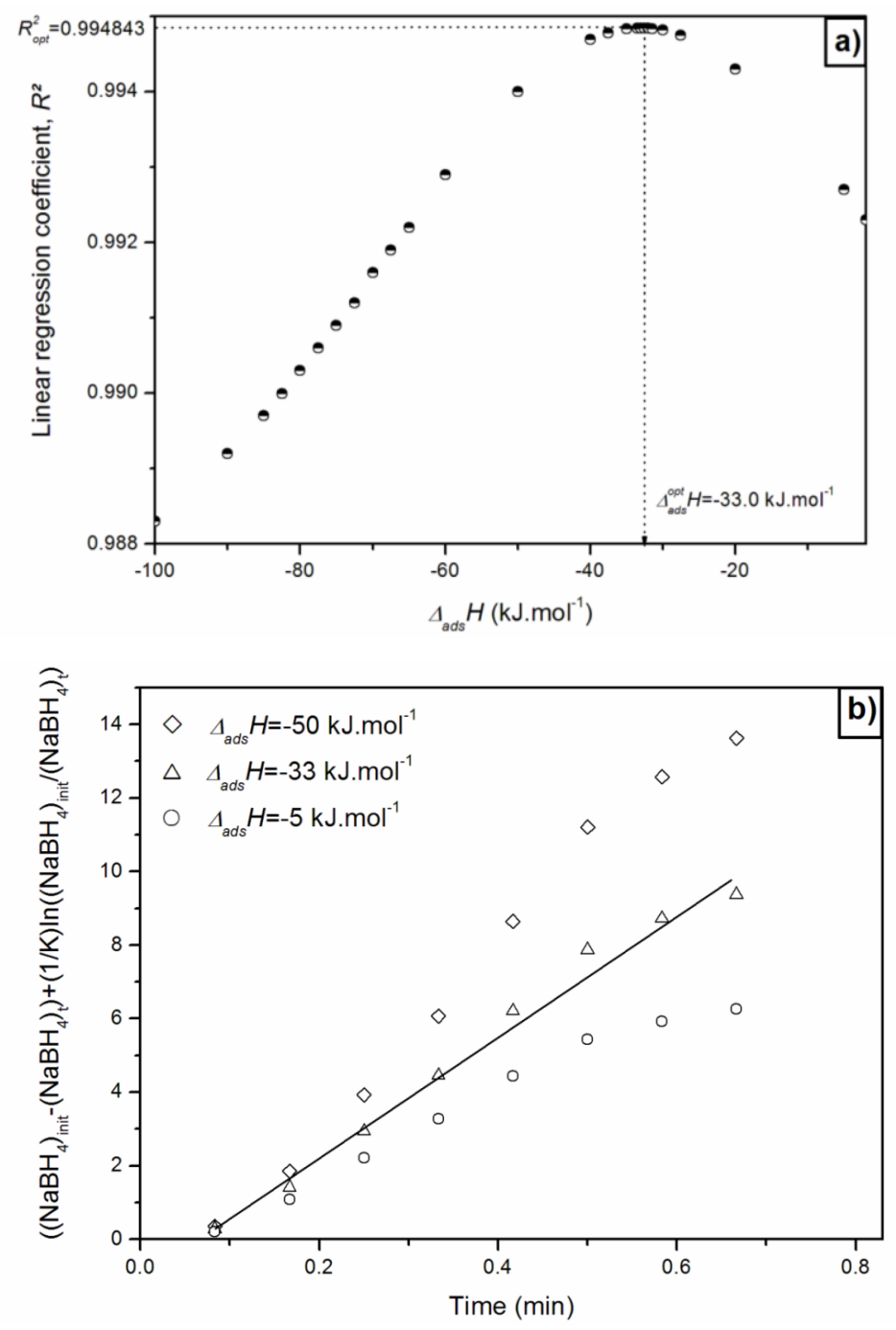

Fig. 5. Optimization of the adsorption enthalpy $\Delta_{\text {ads }} \mathrm{H}$ for the Langmuir-Hinshelwood model in the case of the hydrolysis at $80{ }^{\circ} \mathrm{C}$ (a); the model diverges for $\Delta_{\text {ads }} \mathrm{H}$ values different from $-33.0 \mathrm{~kJ}^{\mathrm{mol}} \mathrm{m}^{-1}$ (b).

The Langmuir-Hinshelwood kinetic model (Eqs. (2), (4) and (5)) was then applied to all of the experiments carried out at $\mathrm{T}>45^{\circ} \mathrm{C}$. This enabled to get $\mathrm{k}_{\mathrm{L}}$ (Table 3 ). The logarithm of $\mathrm{k}_{\mathrm{L}}$ was plotted as a function of $\mathrm{T}^{-1}$ (Fig. 6) in order to calculate $\mathrm{E}_{\mathrm{A}}$ over the range $45-90{ }^{\circ} \mathrm{C}$. It was found to be $60 \pm 9 \mathrm{~kJ} \cdot \mathrm{mol}^{-1}$. This value takes into account both high and low $C_{t}$ whereas the $E_{A}$ of $48 \pm 3 \mathrm{~kJ} \cdot \mathrm{mol}^{-1}$ found with the help of the nth-order model only considers high $C_{t}$ (i.e. zero-order kinetics). 


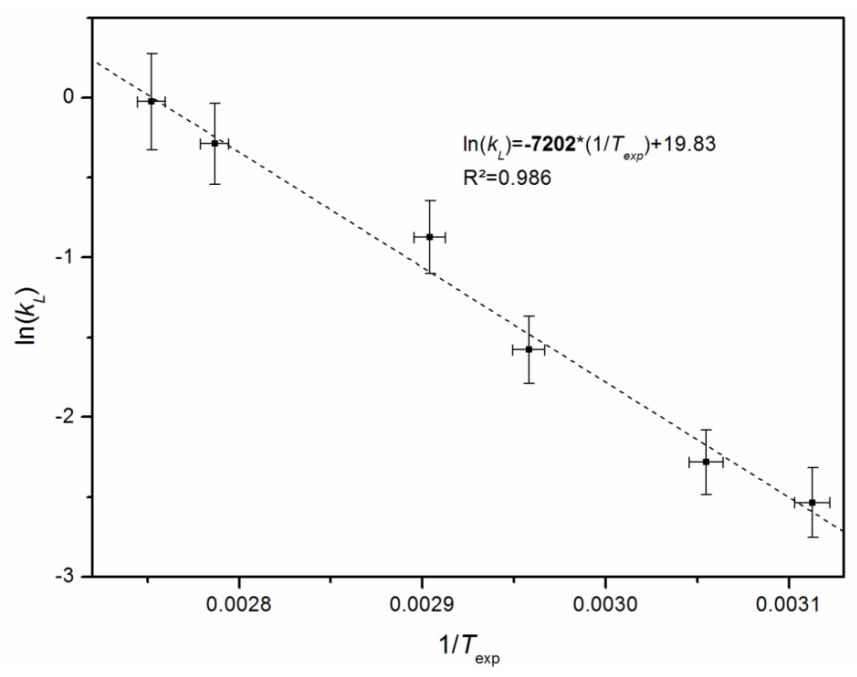

Fig. 6. Arrhenius plot for the Langmuir-Hinshelwood model.

Table 3. Rate constants kL for the Langmuir-Hinshelwood model in the case of the hydrolysis done at $45-90^{\circ} \mathrm{C}$.

\begin{tabular}{llllll}
\hline $\begin{array}{l}T_{\text {set }} \\
\left({ }^{\circ} \mathrm{C}\right)\end{array}$ & $\begin{array}{l}\beta\left(\mathrm{mol} \mathrm{L}^{-1}\right. \\
\left.\mathrm{min}^{-1}\right)\end{array}$ & $\begin{array}{l}\Delta \beta \\
\left(\mathrm{mol} \mathrm{L}^{-1}\right. \\
\left.\mathrm{min}^{-1}\right)\end{array}$ & $R^{2}$ & $\begin{array}{l}k_{\mathrm{L}} \\
\left(\mathrm{mol} \mathrm{min}^{-1}\right. \\
\left.\mathrm{g}^{-1}(\mathrm{Co})\right)\end{array}$ & $\begin{array}{l}\Delta k_{\mathrm{L}} \\
\left(\mathrm{mol} \mathrm{min}^{-1}\right. \\
\left.\mathrm{g}^{-1}(\mathrm{Co})\right)\end{array}$ \\
\hline 45 & 2.1 & 0.2 & 0.9994 & 0.08 & 0.02 \\
50 & 2.6 & 0.2 & 0.9994 & 0.10 & 0.02 \\
60 & 5.1 & 0.5 & 0.9924 & 0.21 & 0.04 \\
70 & 9 & 1 & 0.9955 & 0.42 & 0.10 \\
80 & 18 & 2 & 0.9948 & 0.7 & 0.2 \\
90 & 21 & 4 & 0.9992 & 1.0 & $0.3^{\mathrm{a}}$ \\
\hline
\end{tabular}

a The error is high because the evolution of $\mathrm{H}_{2}$ is very fast at $90{ }^{\circ} \mathrm{C}$.

\subsection{Hydrolysis mechanism}

From our kinetic study, it stands out that the Langmuir-Hinshelwood mechanism explains the hydrolysis of SB in the presence of Co nanoparticles. According to this mechanism, both $\mathrm{BH}_{4}{ }^{-}$and $\mathrm{H}_{2} \mathrm{O}$ adsorb over the Co surface sites. However, the adsorption of both reactants implies that the adsorption sites are of different electronic structure. The adsorption sites are certainly atoms on defect sites with different local electronic density. $\mathrm{BH}_{4}{ }^{-}$should adsorb over electron-rich sites, such as e.g. $\mathrm{O}^{\delta-}$ or $\mathrm{CO}^{0}$, which would transfer their electronic density towards the $\mathrm{B}$ element. $\mathrm{H}_{2} \mathrm{O}$ should adsorb over electron-deficient sites, such as e.g. $\mathrm{Co}^{\delta+}$, which would attract the electronic density of $\mathrm{O}$ of $\mathrm{H}_{2} \mathrm{O}$. Hereafter, these sites will be denoted as $\mathrm{A}$ and $\mathrm{B}$, respectively. It is noteworthy that the nature of the adsorption sites and the nature of the adsorbed hydrolysis intermediates are not well known yet.

Fig. 7 schematizes the hydrolysis mechanism we assume that it occurs. Seven stages are suggested. The hydrolysis starts with the adsorption (I) of $\mathrm{BH}_{4}{ }^{-}$and $\mathrm{H}_{2} \mathrm{O}$ over $\mathrm{A}$ and $\mathrm{B}$, respectively. Then, one of 
the protonic $\mathrm{H}$ of $\mathrm{H}_{2} \mathrm{O}$ interacts with one of the hydridic $\mathrm{H}$ of $\mathrm{BH}_{4}^{-}(\mathrm{II}) ; \mathrm{H}_{2}$ and $\mathrm{BH}_{3}(\mathrm{OH})^{-}$, which is the first adsorbed intermediate (III), form. After that, there are two possibilities. According to Guella et al. [19], $\mathrm{BH}_{3}(\mathrm{OH})^{-}$desorbs (IV.1) and readsorbs over a free site $\mathrm{A}$ and another $\mathrm{H}_{2} \mathrm{O}$ adsorbs over a site $\mathrm{B}(\mathrm{V})$. The second possibility is given by the stage (IV.2); $\mathrm{BH}_{3}(\mathrm{OH})^{-}$remains adsorbed and interacts with another $\mathrm{H}_{2} \mathrm{O}$ molecule (VI) to form $\mathrm{BH}_{2}(\mathrm{OH})_{2}^{-}$; the second $\mathrm{H}_{2}$ evolves. Both routes (IV.1 and IV.2) are likely but (on the basis of parallel studies that are still in progress and will be soon submitted) we believe that the second one preferably occurs in our experimental conditions. The process (IV.1 or IV.2) recurs until that the fourth $\mathrm{H}_{2}$ evolves. Finally, $\mathrm{B}(\mathrm{OH})_{4}{ }^{-}$desorbs (VII). Kaufman and Sen [28] have reported a mechanism where the dissociative chemisorption of $\mathrm{BH}_{4}{ }^{-}$takes place over a metal like e.g. $\mathrm{Co}$ or $\mathrm{Ni}$ to lead to adsorbed $\mathrm{BH}_{3}$ and adsorbed $\mathrm{H}^{-}$. This mechanism suggests the involvement of two different adsorption sites, an electron-rich and an electron-deficient. Further, the adsorption of one $\mathrm{H}^{+}$of $\mathrm{H}_{2} \mathrm{O}$ occurs over a metal site (i.e. electron-rich), with $\mathrm{OH}^{-}$remaining in solution. Finally, adsorbed $\mathrm{H}^{-}$and adsorbed $\mathrm{H}^{+}$interact to form $\mathrm{H}_{2}$ and, in parallel, $\mathrm{BH}_{3}$ combines with $\mathrm{OH}^{-}$to form $\mathrm{BH}_{3}(\mathrm{OH})^{-}$. This mechanism is characterized by zero-order kinetics. It can be compared to that reported in Fig. 7 as both consider the adsorption of $\mathrm{BH}_{4}{ }^{-}$and $\mathrm{H}_{2} \mathrm{O}$; nevertheless they are different by the fact that the adsorption is associative in Fig. 7.

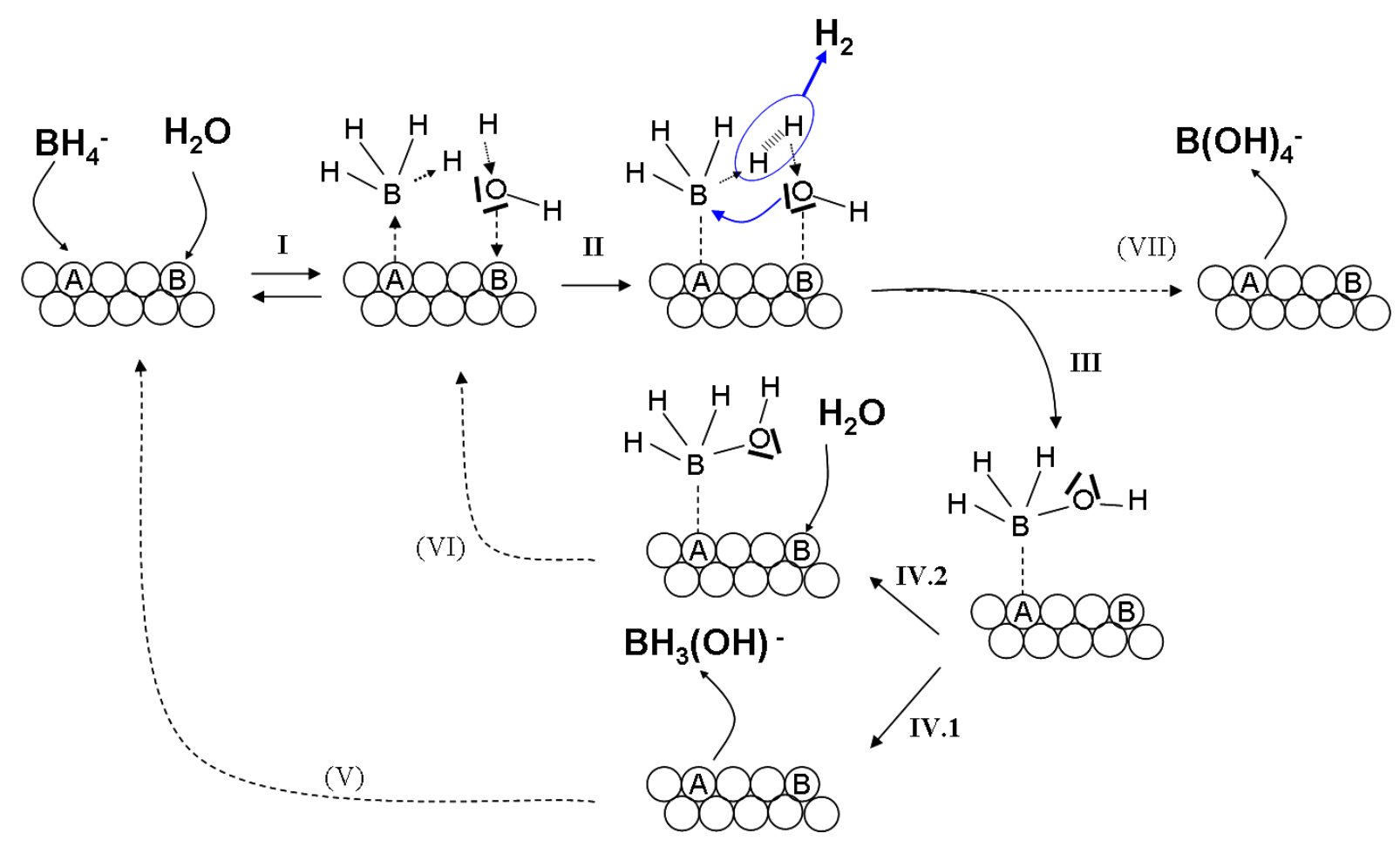

Fig. 7. Schematized Langmuir-Hinshelwood mechanism for hydrolysis of SB catalyzed by Co nanoparticles. 
According to the mechanism, an order of 0 versus $\mathrm{C}_{\mathrm{t}}$ suggests that the amount of $\mathrm{BH}_{4}{ }^{-}$within the diffusion layer nearby the catalyst surface is high enough. This also implies that the A-type surface sites are $\mathrm{BH}_{4}{ }^{-}$-saturated. The predominance of a positive order implies that the RDS is, first, the diffusion and, second, the adsorption of $\mathrm{BH}_{4}{ }^{-}$over the surface sites. Our results are consistent with Zhang et al.'s [12] as well as with Patel et al.'s [23]. In other words, the adsorption process seems to control the changes observed [12].

Today, one of the fundamental challenges is to shed light on the reaction mechanism of SB hydrolysis in the presence of Co catalysts. Several aspects have to be more investigated. Actually, there are several critical questions. Which is the process between (IV.1) and (IV.2) that predominates? Which is the nature of the adsorbed intermediates if the process (IV.2) takes place? Which is the nature of the adsorption sites $A$ and $B$ ? Studies are in progress. However, answering the third question is for the moment difficult, given that there is a controversy about the nature of the catalytically active Co site [11].

\section{Conclusion}

The kinetics of SB hydrolysis is not straightforward because the reaction is complex. Wang and Kang [30] have reported that the complexity is related to occurring solid phase dissolution, liquid phase transfer of the reactant and by-product, and the reactions taking place at the catalyst surface. Few kinetic models fairly describe, in specific experimental conditions, the hydrolysis reaction. And, in the present study, the Langmuir-Hinshelwood model satisfactorily captures the kinetics of the hydrolysis catalyzed by Co nanoparticles.

For the first time, the kinetics of SB hydrolysis was studied over a wide temperature range, i.e. 10-90 ${ }^{\circ} \mathrm{C}$. Further, the hydrolysis conditions were severe in terms of $\mathrm{C}_{0}$. It has been showed that the kinetic parameters, i.e. $n$ and $E_{A}$, vary when $C_{t}$ decreases and $T_{\exp }$ increases. Typically, at $T_{\exp }>45^{\circ} \mathrm{C}, n$ is zero at high $C_{t}$ and is $>0$ at low $C_{t}$. Besides, $E_{A}$ obtained at $10-45{ }^{\circ} \mathrm{C}$ is higher than the value calculated at $45-90{ }^{\circ} \mathrm{C}$. In other words, there is a change in the hydrolysis mechanism, which besides follows the Langmuir-Hinshelwood one. In this mechanism, $\mathrm{BH}_{4}^{-}$and $\mathrm{H}_{2} \mathrm{O}$ adsorb over free active sites (Co and/or $\mathrm{O}$ atoms on defect sites) of the Co catalyst; $\mathrm{BH}_{3} \mathrm{OH}^{-}$and $\mathrm{H}_{2}$ then form. In addition to $\mathrm{n}$ and $\mathrm{E}_{\mathrm{A}}$, the rate constants, the adsorption constant and the adsorption enthalpy were experimentally determined.

The present study is a step forward in highlighting and thus better understanding the hydrolysis mechanisms occurring in the presence of Co-based catalysts, but there is a lot to do. For example, it is still unknown which types of active sites adsorb $\mathrm{BH}_{4}^{-}$and $\mathrm{H}_{2} \mathrm{O}$, knowing that they have to be different (the former should be electron-rich and the latter electron-deficient). Another example is 
related to the nature of the reaction intermediates and their occurrence in the mechanism proposed. Studies, which are especially focused on the (in situ and ex situ) characterization of the used catalyst and on the molecular aspects of the reaction, are in progress. The present one was specifically dedicated to the reaction kinetics.

\section{References}

[1] H.I. Schlesinger, H.C. Brown, A.E. Finholt, J.R. Gilbreath, H.R. Hoekstra, E.K. Hyde, J. Am. Chem. Soc. 75 (1953) 215-219.

[2] U.B. Demirci, P. Miele, C. R. Chim. 12 (2009) 943-950.

[3] J. Zhang, T.S. Fisher, J.P. Gore, D. Hazra, P.V. Ramachandran, Int. J. Hydrogen Energy 31 (2006) 2292-2298.

[4] U.B. Demirci, O. Akdim, J. Andrieux, J. Hannauer, R. Chamoun, P. Miele, Fuel Cells 10 (2010) 335350 , references therein.

[5] U.S. Department of Energy Hydrogen Program, http://www.hydrogen.energy.gov/, Independent review, November 2007, Go/no-go recommendation for sodium borohydride for on-board vehicular hydrogen storage, NREL/MP-150-42220.

[6] E.Y. Marrero-Alfonso, T.A. Davis, M.A. Matthews, Int. J. Hydrogen Energy 32 (2007) 4717-4722.

[7] U.B. Demirci, P. Miele, Energy Environ. Sci. 2 (2009) 627-637.

[8] P. Krishnan, T.H. Yang, W.Y. Lee, C.S. Kim, J. Power Sources 143 (2005) 17-23.

[9] S. Özkar, M. Zahmakıran, J. Alloys Compd. 404-406 (2005) 728-731.

[10] B.H. Liu, Z.P. Li, J. Power Sources 187 (2009) 527-534, references therein.

[11] U.B. Demirci, P. Miele, Phys. Chem. Chem. Phys. 12 (2010) 14651-14665.

[12] J.S. Zhang, W.N. Delgass, T.S. Fisher, J.P. Gore, J. Power Sources 164 (2007) 772-781.

[13] A.J. Hung, S.F. Tsai, Y.Y. Hsu, J.R. Ku, Y.H. Chen, C.C. Yu, Int. J. Hydrogen Energy 33 (2008) 62056215 , references therein.

[14] H.B. Dai, Y. Liang, L.P. Ma, P. Wang, J. Phys. Chem. C 112 (2008) 15886-15892.

[15] U.B. Demirci, F. Garin, J. Mol. Catal. A 279 (2008) 57-62, references therein.

[16] J. Andrieux, D. Swierczynski, L. Laversenne, A. Garron, S. Bennici, C. Goutaudier, P. Miele, A. Auroux, B. Bonnetot, Int. J. Hydrogen Energy 34 (2008) 938-951, references therein.

[17] Ö. Metin, S. Özkar, Energy Fuels 23 (2009) 3517-3526.

[18] A. Garron, D. Swierczynski, S. Bennici, A. Auroux, Int. J. Hydrogen Energy 34 (2009) 1185-1199.

[19] G. Guella, C. Zanchetta, B. Patton, A. Miotello, J. Phys. Chem. B 110 (2006) 17024-17033.

[20] S.R. Gunn, L.G. Green, J. Am. Chem. Soc. 77 (1955) 6197-6198. 
[21] J. Hannauer, U.B. Demirci, G. Pastor, C. Geantet, J.M. Herrman, P. Miele, Energy Environ. Sci. (2010), doi:10.1039/COEE00023J.

[22] S.C. Amendola, S.L. Sharp-Goldman, M.S. Janjua, M.T. Kelly, P.J. Petillo, M. Binder, J. Power Sources 85 (2000) 186-189.

[23] N. Patel, R. Fernandes, A. Miotello, J. Power Sources 188 (2009) 411-420.

[24] Y. Kojima, K. Suzuki, Y. Kawai, J. Power Sources 155 (2006) 325-328.

[25] J.C. Ingersoll, N. Mani, J.C. Thenmozhiyal, A. Muthaiah, J. Power Sources 173 (2007) 450-457.

[26] G.Y. Moon, S.S. Lee, K.Y. Lee, S.H. Kim, K.H. Song, J. Ind. Eng. Chem. 14 (2008) 94-99.

[27] C, . C, akanyıldırım, M. Gürü, Renew. Energy 35 (2010) 839-844.

[28] C.M. Kaufman, B. Sen, J. Chem. Soc. Dalton Trans. (1985) 307-313.

[29] K. Tomishige, A. Okabe, K. Fujimoto, Appl. Catal. A 194/195 (2000) 383-393.

[30] P. Wang, X.D. Kang, Dalton Trans. (2008) 5400-5413. 